\title{
Improving bicycle safety in Canada
}

\author{
Eric Letovsky, MD*; Brian H. Rowe, MD, MSc ${ }^{\dagger}$; Steven Marc Friedman, MD, MPH*; \\ Carolyn Snider, MD, MPH${ }^{\ddagger}$; Emily Sullivan, $\mathrm{MD}^{\S}$
}

\section{EXECUTIVE SUMMARY}

Cycling is a popular recreational and transportation option, especially in urban areas in Canada. Unfortunately, injuries resulting from cycling are common and result in many Emergency Department (ED) presentations, ranging from minor to life threatening.

While it may not be possible to eliminate all cycling injuries in Canada, it should be possible to mitigate their severity and frequency, by addressing a number of important contributing factors.

The most important of these factors are the built environment, the visibility of the cyclists, and the use of bicycle helmets. Addressing and improving each of these factors will help reduce injuries to cyclists.

As emergency physicians, we have a responsibility to advocate for public policy changes that can prevent injury and save lives.

\section{CAEP POSITION}

- CAEP advocates that the recommendations of the Office of the Ontario Chief Coroner's Cycling Death Review be adopted in full by the Province of Ontario, and that the recommendations be distributed to all other provinces for similar adoption.

- CAEP has identified cycling safety issues that should be considered priorities. Specifically, CAEP recommends that:

A) A "complete streets" approach should be adopted to guide the development and redevelopment of communities to give consideration to enhancing safety for all road users, and should include creation of cycling networks (incorporating strategies such as connected cycling lanes, separated bike lanes, bike paths, and other models appropriate to the community), as well as designation of community safety zones in residential areas, with reduced posted maximum speeds and increased fines for speeding;

B) An educational campaign regarding cyclist visibility, especially at night, should be implemented;

C) Bicycle helmet legislation should be amended in all provinces to make helmets mandatory for cyclists of all ages;

D) Bicycle helmet legislation should be approved in provinces without any current law, as soon as possible.

\section{BACKGROUND}

Cycling is a popular recreational and transportation option, especially in urban areas. Unfortunately, injuries resulting from cycling are common. Many of these injuries result in Emergency Department (ED) presentations. These injuries range from minor to severe; unfortunately, death from cycling remains a concern for all who participate in and promote this activity. ${ }^{1}$ A combination of environmental, mechanical, and behavioural factors are involved in most cycling injuries; however, improving the built environment, improving cyclist visibility and mandating helmet use are three important injury prevention initiatives that form the basis of this position paper.

The Office of the Ontario Chief Coroner's Cycling Death Review was released in June 2012. This important provincial review was undertaken as a result

From the *Division of Emergency Medicine, Department of Family and Community Medicine, University of Toronto, Toronto, ON; $\nmid$ Department of Emergency Medicine and School of Public Health, University of Alberta, Edmonton, AB; †Department of Emergency Medicine, University of Manitoba, Winnipeg, MB; and §College of Medicine, University of Saskatchewan, Saskatoon, SK.

Correspondence to: Dr. Eric Letovsky, Department of Emergency Medicine, Trillium Health Partners, 2200 Eglinton Avenue West, Mississauga, ON L5M 2N1; Eric.letovsky@trilliumhealthpartners.ca.

(c) Canadian Association of Emergency Physicians

DOI 10.2310/8000.2014.201402 
of concern, both from the public and within the Coroner's Office, surrounding the issue of cycling safety, and mirrors a previous publication that focused on cycling fatalities. ${ }^{2}$ It examined the circumstances of 129 deaths that occurred from January 1, 2006 to December 31, 2010.3 The findings of the review include recommendations that target infrastructure, education, legislation and enforcement. The main findings of the review were:

- The vast majority of cycling deaths are preventable. The review data supported the conclusion that all of the 129 deaths in this Review could have been prevented. ${ }^{1}$

- Cycling deaths are more likely to occur in those not wearing helmets. Those cyclists whose causes of death included a head injury were three times more likely to not be wearing a helmet compared to those who died of other injuries. ${ }^{3}$

- The proportion of helmet use was very low - only 26 percent of those cyclists killed during the study period were wearing a helmet.

There is a combination of environmental, mechanical, and behavioural factors involved in most cycling injuries in the transportation and recreational setting; understanding these factors can contribute to the development of multifaceted prevention strategies unique to the region of implementation.

\section{IMPROVING THE BUILT ENVIRONMENT}

The "built environment" refers to the surroundings in which human activity such as cycling occurs and includes roads, bike paths/trails, obstacles, intersections and cycling lanes. Evidence from between-country comparisons and from injury research show that modifications to the built environment for cycling offer the greatest opportunity for decreasing cycling injuries and deaths. Such interventions are a primary prevention measure that reduce the risk of crashes occurring and thus prevent injuries to the whole body. Northern European countries, including the Netherlands, Denmark, Germany, Sweden, and Finland have implemented a "complete streets" approach to cycling safety that includes separated bike lanes on major city streets and rural roads to encourage people of all ages to cycle to diverse destinations (e.g., work, school, shopping, social activities). A consequence of this protected infrastructure is dramatically decreased cycling injuries and fatalities compared to statistics in Canada and the United States (2 to more than 10-fold lower). ${ }^{46}$ The value of separated bike lanes and other bicycle-specific infrastructure (i.e., painted bike lanes, off-street bike paths, and residential street bikeways) has also been demonstrated in analytical studies..$^{711}$ In locations where safer infrastructure is only starting to be implemented, large reductions in injuries have been observed within 5 years. ${ }^{12}$

Building safe cycling infrastructure attracts more people to cycling. This has both a safety advantage and a health advantage. International comparisons, among and within-cities over time, demonstrate that increased cycling volumes reduce cycling injuries, called the "safety in numbers" effect. ${ }^{13}$ The health benefits of cycling have also been demonstrated repeatedly. ${ }^{14-18}$ Cycling as a daily transportation option is an easily sustained way to meet physical activity requirements to maintain or reduce weight. These benefits in turn reduce the incidence of the most common chronic diseases of our time, including heart disease, diabetes, dementia, and certain cancers. Studies of the benefits and risks of cycling have overwhelmingly found that these health benefits outweigh injury risks (even in countries with less safe infrastructure). Benefit to risk ratios range from 9:1 to 96:1. ${ }^{14-18}$ These wide-ranging benefits of safe cycling infrastructure have led to a change in transportation design philosophies in cities throughout North America, with the emphasis on bicycle-specific facilities that are both safe and attractive to those of all ages and abilities. ${ }^{19}$

\section{VISIBILITY}

The use of cycling for transportation and recreational purposes has meant that cycling increasingly occurs during periods of sub-optimal lighting. Night-time cycling is particularly problematic, and most jurisdictions legislate the use of reflective clothing, lights and reflective devices. Clear evidence for the most effective strategies for conspicuity is sparse $^{20}$; however, there are some important issues to consider. First, cycling at night represents a particularly high risk activity, which is often exacerbated by concomitant alcohol use. ${ }^{21}$ Second, high visibility clothing (i.e., white, yellow, orange, red) should be encouraged, especially when riding at night and times of limited visibility; however, Canadian data suggests only $33 \%$ of cyclists use these conspicuous colours. ${ }^{22}$ Third, while cyclists themselves advocate visibility aid use by cyclists, they report less than optimal and less frequent use of these aides. ${ }^{23}$ In summary, clothing colour, reflectivity, and lights are 
strongly encouraged for cyclists at all times to increase visibility and reduce the risk of interactions with motorized vehicles.

Despite the efforts of urban planners to retrofit many Canadian cities to improve the built environment for cyclists, and educational efforts to increase conspicuity of cyclists, crashes remain a major safety concern. Most problematic of these crashes is the motor-vehicle vs cyclist collision. Efforts to protect cyclists in the event of a crash require continued vigilance.

\section{HELMET STRATEGY}

There is now relatively strong evidence that bicycle helmets reduce face and head injuries. ${ }^{24}$ A Cochrane systematic review reported that helmets reduce the risk of head, brain and severe brain injury for all cycling ages by 63-88\%. Helmets appear to provide protection for crashes involving motor vehicles (69\%) and crashes from all other causes (68\%). Injuries to the upper and mid facial areas are reduced $65 \% .{ }^{24}$ While many reports suggest cycle helmet wearing is not compliant with recommendations, ${ }^{25}$ the use of any helmet provides protection.

Despite the knowledge above and public relations campaigns, convincing cyclists to wear helmets remains difficult. This is particularly so for adolescents, males and adults. For example, observations and surveys reveal low helmet use in both adults and adolescents. In Alberta, prior to helmet legislation overall cyclist helmet wearing was $55 \%,{ }^{26}$ which mirrors a recent Quebec observational result where helmet use was $46 \% .{ }^{27}$ Many researchers and injury prevention advocates suggest that without legislation, a "ceiling effect" has been reached in helmet wearing.

The evidence for helmet legislation increasing helmet use has been summarized in two systematic reviews. ${ }^{25,28}$ In both reviews, helmet legislation increased helmet use, especially in locations where helmet use was previously low. Much debate exists about legislation, and much of it focuses on the role of children-only compared to universal helmet legislation. Various jurisdictions have introduced mandatory helmets for all ages. Nova Scotia enacted all-age bicycle helmet legislation in 1997. Bicycle helmets are mandatory in all states and territories in Australia for all ages; the same is true for New Zealand. Conversely, in Canada, some provinces have legislation that covers children/adolescents while others have none (see Table).

\begin{tabular}{|c|c|c|}
\hline Province/territory & Legislation & Year \\
\hline New Brunswick & All ages & December 1995 \\
\hline British Columbia & All ages & September 1996 \\
\hline Nova Scotia & All ages & July 1997 \\
\hline Prince Edward Island & All ages & July 2003 \\
\hline Ontario & Under 18 only & October 1995 \\
\hline Alberta & Under 18 only & May 2002 \\
\hline Manitoba & Under 18 only & May 2013 \\
\hline Saskatchewan & None & \\
\hline Quebec & None & \\
\hline Newfoundland & None & \\
\hline $\begin{array}{l}\text { Yukon, Northwest, and } \\
\text { Nunavut Territories }\end{array}$ & None & \\
\hline
\end{tabular}

Opponents of legislation often ask: What is the evidence for the effectiveness of helmet legislation? In the state of Victoria, Australia, a new law requiring helmets in 1990 increased the use of helmets from 31\% to $75 \%$ in adult recreational cyclists in less than a year. These changes were associated with a $47 \%$ reduction in overall head injuries and lower hospital admissions (a measure of severity) for head injuries in cyclists. ${ }^{29} \mathrm{~A}$ 2010 Canadian study showed that youth and adults are significantly more likely to wear helmets as the comprehensiveness of helmet legislation increases, and that helmet legislation is not associated with changes in ridership. ${ }^{30}$ Alberta's helmet law was met with increased helmet use, especially in the target age groups. ${ }^{31}$ More importantly, a study of two juxtaposed regions with children-only and universal helmet laws in Alberta demonstrated increased helmet use in the municipality with a universal helmet law. ${ }^{32}$ Finally, and importantly, another Canadian study demonstrated reduction in ED visits and hospitalizations for head injury following the introduction of a mandatory child/ adolescent only helmet law. ${ }^{33}$

\section{INCREASING HELMET USE}

A recent literature review by the Cochrane Collaboration suggested that bicycle helmet legislation appears to be effective in increasing helmet use and decreasing head injury rates in the populations for which it is implemented. There are very few high quality evaluative studies that measure these outcomes, and none that reported data on possible declines in bicycle use. ${ }^{34}$

Helmet legislation is not without theoretical risks. For example, some wonder if the inconvenience of 
helmets will deter participation in this recreational activity and contribute to the obesity epidemic. ${ }^{35}$ While some initial decline in participation has been reported following the implementation of helmet laws, cycling activity recovery appears to be rapid for most jurisdictions. Second, while the costs of helmets have declined over the years, this may remain a barrier for some lower socioeconomic regions. Moreover, subsidy programs in such locations may counter this barrier. Third, the heavy, uncomfortable helmets of earlier years have been replaced by sleek, colourful, and more comfortable helmets. Nonetheless, these features may represent barriers for some cyclists and further design changes may be possible. Fourth, enforcement has been problematic with one province reporting virtually no tickets issued..$^{31}$ Others prefer a positive reinforcement program of rewarding good behaviour. Finally, given the multi-factorial nature of most cycling crashes, the focus on helmets cannot be at the exclusion of other important injury prevention considerations (e.g., bike lanes, speed restriction, visibility aides, and bike maintenance).

Finally, the immediate and long-term costs and consequences of caring for anyone who sustains a bikerelated severe injury is high, especially when head injury is involved. The health economic perspective of this issue is beyond the scope of this paper; however, the prevention of even one injury seems "cost effective." Nonetheless, economic evaluations have been performed specifically on helmet laws and suggest preventing childhood head injuries achieves the greatest savings. ${ }^{36}$ In addition, any bike injury prevention intervention that reduces ED visits and hospitalizations would likely save money; calls to implement effective injury prevention strategies like these have been made for decades. ${ }^{37}$

\section{SUMMARY}

Road safety is a paramount concern for emergency physicians. Cyclists are among the most vulnerable road users and are at risk for potentially catastrophic injuries. As emergency physicians, we regularly witness the consequences of failures to adequately protect cyclists by providing street safety infrastructure as well as the lack of universal helmet use. These consequences include, but are not limited to: scalp lacerations, concussions, facial injuries, and other life threatening brain and torso injuries. Most of the recommendations contained in the review fall outside the jurisdiction of cities and municipalities and require changes to provincial legislation. As emergency physicians, however, we have a responsibility to advocate for public policy change that could mitigate the consequence of cycling crashes.

Acknowledgements: The authors would like to thank Dr. Atul Kapur, University of Ottawa, for his thoughtful review of the manuscript. The authors appreciate the assistance of Mrs. Diane Milette (University of Alberta) in manuscript preparation.

Competing interests: Dr. Brian Rowe is supported as a Tier I Canada Research Chair in Evidence-based Emergency Medicine by the Canadian Institutes of Health Research (CIHR) through the Government of Canada (Ottawa, Ontario). The authors declare no other conflicts.

\section{REFERENCES}

1. Office of the Chief Coroner for Ontario. Cycling death review: a review of all accidental cycling deaths in Ontario from January 1st, 2006 to December 31st, 2010.

2. Rowe BH, Rowe AM, Bota GW. Bicyclist and environmental factors associated with fatal bicycle-related trauma in Ontario. CMA7 1995;152:45-53.

3. Persaud N, Coleman E, Zwolakowski D, et al. Nonuse of bicycle helmets and risk of fatal head injury: a proportional mortality, case-control study. CMAf 2012;184:E921-3, doi:10.1503/cmaj.120988.

4. International Traffic Safety Data and Analysis Group. IRTAD road safety 2010 annual report. OECD/ITF. 2011.

5. Beck LF, Dellinger AM, O’Neil ME. Motor vehicle crash injury rates by mode of travel, United States: using exposurebased methods to quantify differences. Am 7 Epidemiol 2007; 166:212-8, doi:10.1093/aje/kwm064.

6. Pucher J, Buehler R. Making cycling irresistible: lessons from the Netherlands, Denmark and Germany. Transport Rev 2008;28:495-528, doi:10.1080/01441640701806612.

7. Reynolds CC, Harris MA, Teschke K, et al. The impact of transportation infrastructure on bicycling injuries and crashes: a review of the literature. Environ Health 2009;8: 47, doi:10.1186/1476-069X-8-47.

8. Teschke K, Harris MA, Reynolds CC, et al. Route infrastructure and the risk of injuries to bicyclists: a casecrossover study. Am 7 Public Health 2012;102:2336-43, doi:10.2105/AJPH.2012.300762.

9. Harris MA, Reynolds CC, Winters M, et al. Comparing the effects of infrastructure on bicycling injury at intersections and non-intersections using a case-crossover design. Inj Prev 2013;19:303-10, doi:10.1136/injuryprev-2012-040561.

10. Lusk AC, Furth PG, Morency P, et al. Risk of injury for bicycling on cycle tracks versus in the street. Inj Prev 2011; 17:131-5, doi:10.1136/ip.2010.028696.

11. Lusk AC, Morency P, Miranda-Moreno LF, et al. Bicycle guidelines and crash rates on cycle tracks in the United 
States. Am 7 Public Health 2013;103:1240-8, doi:10.2105/ AJPH.2012.301043.

12. Olivier J, Walter SR, Grzebieta RH. Long term bicycle related head injury trends for New South Wales, Australia following mandatory helmet legislation. Accid Anal Prev 2013;50:1128-34, doi:10.1016/j.aap.2012.09.003.

13. Jacobsen PL. Safety in numbers: more walkers and bicyclists, safer walking and bicycling. Inj Prev 2003;9:205-9, doi:10. 1136/ip.9.3.205.

14. Johan de Hartog J, Boogaard H, Nijland H, Hoek G. Do the health benefits of cycling outweigh the risks? Environ Health Perspect 2010;118:1109-16, doi:10.1289/ehp.0901747.

15. Rabl A, de Nazelle A. Benefits of shift from car to active transport. Transport Policy 2012;19:121-31, doi:10.1016/ j.tranpol.2011.09.008.

16. Rojas-Rueda D, de Nazelle A, Tainio M, Nieuwenhuijsen MJ. The health risks and benefits of cycling in urban environments compared with car use: health impact assessment study. BM7 2011;343:d4521, doi:10.1136/bmj.d4521.

17. Grabow ML, Spak SN, Holloway T, et al. Air quality and exercise-related health benefits from reduced car travel in the midwestern United States. Environ Health Perspect 2012;120: 68-76, doi:10.1289/ehp.1103440.

18. Woodcock J, Edwards P, Tonne C, et al. Public health benefits of strategies to reduce greenhouse-gas emissions: urban land transport. Lancet 2009;374:1930-43, doi:10.1016/ S0140-6736(09)61714-1.

19. Schmitt A. The rise of protected bike lanes in North America. Momentum 2013;62:56-69. Available at: http:// momentummag.com/features/protected-bike-lanes-by-thenumbers/\#sthash.EDmmcmR2.dpbs.

20. Kwan I, Mapstone J. Visibility aids for pedestrians and cyclists: a systematic review of randomised controlled trials. Accid Anal Prev 2004;36:305-12, doi:10.1016/S00014575(03)00008-3.

21. Andersson AL, Bunketorp O. Cycling and alcohol. Injury 2002;33:467-71, doi:10.1016/S0020-1383(02)00028-1.

22. Teschke K, Brubacher JR, Friedman SM, et al. Personal and trip characteristics associated with safety equipment use by injured adult bicyclists: a cross-sectional study. BMC Public Health 2012;12:765, doi:10.1186/1471-2458-12-765.

23. Wood JM, Lacherez PF, Marszalek RP, King MJ. Drivers' and cyclists' experiences of sharing the road: incidents, attitudes and perceptions of visibility. Accid Anal Prev 2009; 41:772-6, doi:10.1016/j.aap.2009.03.014.

24. Thompson DC, Rivara FP, Thompson R. Helmets for preventing head and facial injuries in bicyclists. Cochrane Database Syst Rev 2001;(2):CD001855.
25. Hagel BE, Lee RS, Karkhaneh M, et al. Factors associated with incorrect bicycle helmet use. Inj Prev 2010;16:178-84, doi:10.1136/ip.2009.023994.

26. Nykolyshyn K, Petruk JA, Wiebe N, et al. The use of bicycle helmets in a western Canadian province without legislation. Can 7 Public Health 2003;94:144-8.

27. Grenier T, Deckelbaum DL, Boulva K, et al. A descriptive study of bicycle helmet use in Montreal, 2011. Can 7 Public Health 2013;104:e400-4.

28. Karkhaneh M, Kalenga JC, Hagel BE, Rowe BH. Effectiveness of bicycle helmet legislation to increase helmet use: a systematic review. Inj Prev 2006;12:76-82, doi:10. 1136/ip.2005.010942.

29. Vulcan AP, Cameron MH, Watson WL. Mandatory bicycle helmet use: experience in Victoria, Australia. World 7 Surg 1992;16:389-97, doi:10.1007/BF02104437.

30. Dennis J, Potter B, Ramsay T, Zarychanski R. The effects of provincial bicycle helmet legislation on helmet use and bicycle ridership in Canada. Inj Prev 2010;16:219-24, doi:10. 1136/ip.2009.025353.

31. Karkhaneh M, Rowe BH, Saunders LD, et al. Bicycle helmet use four years after the introduction of helmet legislation in Alberta, Canada. Accid Anal Prev 2011;43:788-96, doi:10.1016/j.aap.2010.10.026.

32. Karkhaneh M, Rowe BH, Saunders LD, et al. Bicycle helmet use after the introduction of all ages helmet legislation in an urban community in Alberta, Canada. Can $\mathcal{F}$ Public Health 2011;102:134-8.

33. Karkhaneh M, Rowe BH, Saunders LD, et al. Trends in head injuries associated with mandatory bicycle helmet legislation targeting children and adolescents. Accid Anal Prev 2013;59:206-12, doi:10.1016/j.aap.2013.05.027.

34. Macpherson A, Spinks A. Bicycle helmet legislation for the uptake of helmet use and prevention of head injuries. Cochrane Database Syst Rev 2008;(3):CD005401.

35. Robinson DL. Bicycle helmet legislation: can we reach a consensus? Accid Anal Prev 2007;39:86-93, doi:10.1016/ j.aap.2006.06.007.

36. Naumann RB, Dellinger AM, Zaloshnja E, et al. Incidence and total lifetime costs of motor vehicle-related fatal and nonfatal injury by road user type, United States, 2005. Traffic Inj Prev 2010;11:353-60, doi:10.1080/15389588.2010.486429.

37. Miller TR, Levy DT. Cost-outcome analysis in injury prevention and control: eighty-four recent estimates for the United States. Med Care 2000;38:562-82, doi:10.1097/ 00005650-200006000-00003. 